\title{
Functional Characterization of Pknl-Rv2159c Interaction in Redox Homeostasis of Mycobacterium tuberculosis
}

\author{
Arunkumar Venkatesan ${ }^{1}$, Kannan Palaniyandi ${ }^{1}$, Divakar Sharma ${ }^{2}$, Deepa Bisht ${ }^{2}$ and \\ Sujatha Narayanan ${ }^{1 *}$
}

${ }^{1}$ Department of Immunology, National Institute for Research in Tuberculosis, Chennai, India, ${ }^{2}$ Department of Biochemistry,

National JALMA Institute for Leprosy and other Mycobacterial Diseases, Agra, India

\section{OPEN ACCESS}

Edited by:

Fumito Maruyama,

Kyoto University, Japan

Reviewed by:

Yukiko Nishiuchi,

Osaka City University, Japan

Masaaki Nakayama

Okayama University, Japan

${ }^{*}$ Correspondence:

Sujatha Narayanan

sujatha.sujatha36@gmail.com

Specialty section:

This article was submitted to

Infectious Diseases,

a section of the journal

Frontiers in Microbiology

Received: 27 July 2016 Accepted: 04 October 2016 Published: 21 October 2016

Citation:

Venkatesan A, Palaniyandi K

Sharma $D$, Bisht $D$ and Narayanan $S$ (2016) Functional Characterization of

Pknl-Rv2159c Interaction in Redox

Homeostasis of Mycobacterium

tuberculosis. Front. Microbiol. 7:1654.

doi: 10.3389/fmicb.2016.01654
Mycobacterium tuberculosis adapts to stress conditions by responding to the signals from its external environment. M. tuberculosis genome encodes 11 eukaryotic like serine/threonine protein kinases (STPK) and their importance in regulating the physiology and virulence of the bacteria are being explored. Previous study from our lab identified the M. tuberculosis STPK, Pknl interacts with two peroxidase proteins such as Rv2159c and Rv0148. In this study, we have characterized the biological function behind the Pknl-Rv2159c interaction in M. tuberculosis. Point mutation of Ala-Gly-Trp motif identified that only Ala49 and Gly50 amino acids of Rv2159c are responsible for interaction and there is no phosphorylation involved in the Pknl-Rv2159c interaction. Rv2159c is a member from the carboxymuconolactone decarboxylase family with peroxidase activity. Enzymatic assays with catalytic site point mutants showed that Cys84 of Rv2159c was responsible for its alkylhydroperoxidase activity. Interestingly, interaction with Pknl increased its peroxidase activity by several folds. Gene knockdown of Rv2159c in M. tuberculosis showed increased sensitivity to peroxides such as cumene hydroperoxide and hydrogen peroxide. Proteomic analysis of differentially expressing Rv2159c strains by 2D gel electrophoresis and mass spectrometry revealed the differential abundance of 21 proteins. The total absence of oxidoreductase, GuaB1 suggests the essential role of Rv2159c in redox maintenance. Our findings provide new insights on signaling mechanisms of Pknl in maintaining the redox homeostasis during oxidative stresses.

Keywords: Pknl, Rv2159c, antisense knockdown, alkylhydroperoxidase, protein-protein interactions, 2D gel electrophoresis

\section{INTRODUCTION}

Tuberculosis (TB) is an infectious disease, caused by one of the most successful human pathogen, Mycobacterium tuberculosis. World health organization (WHO) estimated about 1.5 million TB deaths and 9 million new TB cases in 2013 (World Health Organisation, 2014). Furthermore, the increased emergence of multidrug-resistant (MDR), extensively drug-resistant (XDR) TB and HIV-TB co-infection remains a global health concern (Kaufmann and Parida, 2007). 
Proteins do not act isolated inside the living cells, rather they perform their functions by interacting with respective substrates. In $M$. tuberculosis, the signal transduction is largely controlled by eukaryotic like STPKs, two-component signal transduction systems (TCS) and extra cytoplasmic function sigma factors (Bretl et al., 2011). The presence of equal numbers of STPKs and TCSs suggests the complex signaling mechanism of the bacteria (Av-Gay and Everett, 2000). PknI is one of the eleven STPKs in M. tuberculosis was shown to be important for balanced growth during acidic $\mathrm{pH}$ and low oxygen environments. In addition, loss of $p k n I$ leads to hypervirulence in both in vitro and in vivo infection models (Gopalaswamy et al., 2009). Previous study from our lab identified the physical interaction between STPK, PknI and Rv2159c. The study also suggest Ala-Gly-Trp motif of $\mathrm{Rv} 2159 \mathrm{c}$ is responsible for PknI interaction (Venkatesan et al., 2015).

Inside the host, $M$. tuberculosis preferentially replicates in the macrophages and later they recruit lymphocytes and dendritic cells to form granulomas. During the course of infection, $M$. tuberculosis is exposed to reactive oxygen species (ROS) and reactive nitrogen species (RNS) generated by the host immune system (Macmicking et al., 1997; Cooper et al., 2000). To counteract these stresses, $M$. tuberculosis uses a variety of antioxidant defense mechanisms before they damage the cell organelles. oxyR and soxR are the two major global regulators that regulate the prokaryotes against peroxides and superoxides respectively. Despite the loss of functional $\operatorname{oxy} R$ in $M$. tuberculosis, the peroxide stress is managed by its close homolog $a h p C$, an alkylhydroperoxide reductase that detoxifies the organic peroxides (Deretic et al., 1995; Guimaraes et al., 2005). M. tuberculosis strains resistant to isoniazid drug were observed to be devoid of peroxidase activity. However, the mutations associated with $k a t G$ were compensated by increased expression of $a h p C$ and thereby controlling the oxidative and nitrosative stress conditions (Sherman et al., 1996). Additionally, its nonhomolog protein $\mathrm{AhpD}$, a low reactive alkylhydroperoxidase of $M$. tuberculosis also helps in reducing the disulfide bridge formation between the cysteine amino acids (Hillas et al., 2000).

Rv2159c is one of the conserved hypothetical proteins of $M$. tuberculosis. The closely related orthologs suggested that Rv2159c belongs to the family of alkylhydroperoxidases. It also shares its sequence homology with other mycobacterial members such as $M$. bovis, $M$. africanum, $M$. caprae, $M$. canetti, and $M$. orygis. The protein has a carboxymucanolactone decarboxylase (CMD) domain in its structure and appears to contain two catalytic site cysteine residues Cys-Pro-Try-Cys, responsible for peroxidase activity. Rv2159c is present adjacent to the $d c w$ operon in the genome and it forms a separate operon with two uncharacterized genes such as Rv2160c and Rv2161c (Munshi et al., 2013). The expression of Rv2159c was identified to specifically increase only in the virulent $M$. tuberculosis than in the avirulent $M$. tuberculosis H37Ra and M. bovis (Golby et al., 2007; Li et al., 2010). However, the molecular function of alkylhydroperoxidase, Rv2159c remains uncharacterized.

In this study, we report the cloning, expression, purification and catalytic characterization of Rv2159c variants. Furthermore, the in vitro protein interaction studies showed the PknI interacts with Rv2159c through phosphorylation independent manner and the Ala49 and Gly50 amino acids of Rv2159c is needed for the interaction. In addition, we also investigated the functional role of Rv2159c in M. tuberculosis by using an antisense RNA approach. The Rv2159c gene knockdown strain showed increased in vitro growth rate and decreased resistance to peroxide mediated killing. Proteomic approaches identified the probable interacting proteins for Rv2159c. The results suggested that PknI activates Rv2159c during oxidative stress conditions of the bacteria and thereby maintains the cellular homeostasis.

\section{MATERIALS AND METHODS}

\section{Plasmids, Bacterial Strains and Media}

All plasmids and constructs are listed in Table S1 and oligonucleotides are listed in Table S2. The Escherichia coli strains $\mathrm{DH} 5 \alpha$ and BL21 (DE3) (Invitrogen) were used for cloning and expression of recombinant proteins. E. coli cells were grown in luria bertani (LB) medium with constant shaking at $37^{\circ} \mathrm{C}$. M. tuberculosis $\mathrm{H} 37 \mathrm{Rv}$ strain was grown in Middlebrook 7H9 broth (Difco) supplemented with $10 \%$ oleic acid-albumindextrose-catalase (OADC), $0.2 \%$ glycerol and $0.05 \%$ Tween 80 or $7 \mathrm{H} 10$ agar (Difco) supplemented with $\mathrm{OADC}$ at $37^{\circ} \mathrm{C}$. The following antibiotics were supplemented: ampicillin at $50 \mu \mathrm{g} / \mathrm{ml}$ for E. coli and kanamycin $(40 \mu \mathrm{g} / \mathrm{ml}$ for E. coli and $20 \mu \mathrm{g} / \mathrm{ml}$ for M. tuberculosis) whenever needed.

\section{Cloning, Overexpression and Purification of Rv2159c}

M. tuberculosis genomic DNA was isolated using CTAB-NaCl method as described previously (Baess, 1974). The coding region of Rv2159c from M. tuberculosis was amplified by PCR using respective oligonucleotide primers (Table S2). PCR amplified $\mathrm{Rv} 2159 \mathrm{c}$ gene was further cloned into pGEX 4T-1 vector harboring tac promoter. The resultant clone was confirmed through restriction digestion and DNA sequencing.

For recombinant protein expression, the pDVA 2159-GST clone was transformed into E. coli BL21 (DE3) cells and protein synthesis was induced with $0.5 \mathrm{mM}$ isopropyl $\beta$-D-1thiogalactopyranoside (IPTG). The induced cells were grown for $4 \mathrm{~h}$ at $37^{\circ} \mathrm{C}$ and cells were harvested by centrifugation at $6000 \times$ $\mathrm{g}$ for $10 \mathrm{~min}$. The cell pellet was re-suspended in buffer A (50 mM Tris chloride pH: 8, $300 \mathrm{mM} \mathrm{NaCl}, 20 \%$ Glycerol, and 0.5 mM Phenyl methyl sulfonyl fluoride) and sonicated at $2.5 \mathrm{~Hz}$ on ice using ultrasonic homogenizer FS-600N (6 cycles; $30 \mathrm{~s}$ pulse and $1 \mathrm{~min}$ rest). The lysate was centrifuged at $15,000 \times \mathrm{g}$ for 15 min at $4^{\circ} \mathrm{C}$. The crude lysate containing proteins was bound to glutathione sepharose resin (Amersham) and incubated at $8^{\circ} \mathrm{C}$ in end-to-end shaker for $2 \mathrm{~h}$. Column was washed with 8 column volumes of buffer A and the recombinant GST tagged Rv2159c protein was eluted with buffer A containing $20 \mathrm{mM}$ of reduced glutathione. The resultant fractions were dialyzed against $0.5 \mathrm{X}$ buffer $\mathrm{A}$, concentrated and stored at $-80^{\circ} \mathrm{C}$ until further use.

\section{Site Directed Mutagenesis}

The active and catalytic sites of Rv2159c were mutated using QuickChange II XL site directed mutagenesis (SDM) kit 
(Stratagene, Germany) as described by the manufacturer. The pDVA 2159-GST plasmid was used as a template to create the isogenic forms. Mutagenic primers were designed to modify the respective amino acids such as A49P, G50A, W51A, C81S, and C84S. Combinations of mutations were also generated at A49/50/51P and C81/84S. The PCR amplified mutated DNAs were digested with $D p n I$ and further transformed into E. coli BL21 (DE3) cells. All the mutations were verified with DNA sequencing.

\section{Pull Down Assay}

Affinity pull-down assay was performed in Poly-Prep chromatography columns (Bio-Rad, USA) with NiNitrilotriacetic acid (Ni-NTA) resin (Invitrogen, USA) and glutathione sepharose resin (Amersham) respectively. The recombinant His-PknI was over-expressed and purified as mentioned (Gopalaswamy et al., 2004). The nickel affinity pull down was performed by incubating the cytoplasmic crude lysate containing recombinant His-PknI protein with Ni-NTA resin for $2 \mathrm{~h}$ at $4{ }^{\circ} \mathrm{C}$ under gentle agitation. The columns were washed with buffer A containing $40 \mathrm{mM}$ imidazole and incubated with the cytoplasmic crude lysate containing GST-Rv2159c recombinant protein for $4 \mathrm{~h}$ at $4^{\circ} \mathrm{C}$ under gentle agitation. Unbound proteins were removed by washing the column with 10 column volumes of buffer A. The interacting proteins were eluted with buffer A containing $200 \mathrm{mM}$ imidazole. In the same way, glutathione affinity pull down assay was also performed by incubating the crude lysates containing recombinant GST-Rv2159c and His$\mathrm{PknI}$ proteins with glutathione sepharose resin and eluted using buffer A containing $20 \mathrm{mM}$ reduced glutathione. Eluted proteins were separated by SDS-PAGE and subjected to far-western blotting (FWB).

\section{Far-Western Blotting}

The pull down assay eluted interacting proteins was separated on a $10 \%$ SDS-PAGE gel, transferred to polyvinylidene flouride (PVDF) membrane and subjected to FWB as mentioned with slight modifications ( $\mathrm{Wu}$ et al., 2007). The proteins in the membrane was refolded by incubation with $6 \mathrm{M}, 3 \mathrm{M}, 1 \mathrm{M}$, and then $0.1 \mathrm{M}$ Guanidine- $\mathrm{HCl}$ in $\mathrm{AC}$ buffer $(5 \mathrm{M} \mathrm{NaCl}, 1 \mathrm{M}$ Tris, pH:7.5, 0.5 M EDTA, 10\% Tween-20, 2\% Skim milk powder, $10 \%$ Glycerol, and $1 \mathrm{M} \mathrm{DTT}$ ) for $30 \mathrm{~min}$ at room temperature (RT). Then, the blot was completely renatured with AC buffer and left overnight at $4^{\circ} \mathrm{C}$. The membrane was then blocked with 5\% skimmed milk and incubated with purified bait proteins, His-PknI and GST-Rv2159c respectively for 6-7 h at $4{ }^{\circ} \mathrm{C}$. Further, the membrane was probed with anti-His and anti-GST antibodies respectively and visualized using enhanced chemiluminescent (ECL) detection. The intensity of protein bands was also quantified using densitometer scanning and Quantity One software (Bio-Rad, USA). Finally, the percentage difference in expression was quantified using the formula, $\left(\left(\mathrm{V}_{1}-\mathrm{V}_{2}\right) /\left(\left(\mathrm{V}_{1}+\mathrm{V}_{2}\right) / 2\right)\right) * 100$.

\section{In vitro Kinase Assay}

Phosphorylation reactions were carried out using $\left[\gamma_{-}{ }^{32} \mathrm{P}\right]$ ATP (BRIT, Hyderabad) as the phosphate donor in kinase buffer (20
$\mathrm{mM}$ Tris-HCl, $\mathrm{pH}$ 7.5, $5 \mathrm{mM} \mathrm{MgCl} 2,1 \mathrm{mM}$ DTT). Briefly, the PknI and Rv2159c proteins were incubated with kinase buffer in the presence of $5 \mu \mathrm{Ci}$ of $\left[\gamma^{-32} \mathrm{P}\right]$ ATP for $30 \mathrm{~min}$ at $25^{\circ} \mathrm{C}$. The reactions were stopped by the addition of SDSPAGE sample buffer and heated at $95^{\circ} \mathrm{C}$ for $5 \mathrm{~min}$. The samples were separated by SDS-PAGE, gels were dried and analyzed by autoradiography. Control reactions were also performed in kinase buffer containing $\left[\gamma_{-}{ }^{32} \mathrm{P}\right]$ ATP without proteins or with non-specific protein.

\section{HPLC Analysis for Enzyme Activity of Rv2159c}

The Rv2159c, Rv2159c_C81S, Rv2159c_C84S, Rv2159c_C81/84S, PknI-Rv2159c complex proteins and the substrate, cumene hydroperoxide (CHP) (Sigma) in equal concentration $(5 \mu \mathrm{M})$ were equilibrated in KPi buffer (50 mM KPi, pH 7.0, $100 \mathrm{mM}$ $\mathrm{KCl}, 0.1 \mathrm{mM}$ EDTA, and 5\% Glycerol) for $120 \mathrm{~min}$. The reaction was then stopped by addition of an equal volume of $6 \%$ acetic acid in acetonitrile. Reaction mixture was centrifuged and the supernatant was injected onto a Hewlett-Packard 1090 HPLC system equipped with an Axxiom ODS $(4.6 \times 250 \mathrm{~mm})$ reverse phase HPLC column. The detector was set at $260 \mathrm{~nm}$ and the products were separated using 20\% acetonitrile and $80 \%$ water at a flow rate of $1 \mathrm{ml} / \mathrm{min}$. Control reactions were also performed in same KPi buffer without the enzyme or with a non-specific protein Ffh or with $\mathrm{PknI}$ protein alone. The decomposed product, Acetophenone was measured along with acetophenone analytical standard (Sigma) under identical elution conditions.

\section{DTT-Dependent Activity Assay}

The rate of dithiotheritol (DTT) oxidation catalyzed by WT and catalytic site mutants of Rv2159c in the presence of peroxide substrate (tert-butyl hydroperoxide) was measured by absorbance at $310 \mathrm{~nm}$. The WT and catalytic site mutants (Rv2159c_C81S, Rv2159c_C84S, Rv2159c_C81/84S) of Rv2159c were incubated in a buffer $(100 \mathrm{mM} \mathrm{KPi}, \mathrm{pH} 7.0,1 \mathrm{mM}$ EDTA, and $10 \mathrm{mM}$ DTT) with and without DTT at $25^{\circ} \mathrm{C}$ for $0,2,4$, and $6 \mathrm{~min}$. The initial rates were corrected for the background oxidation of DTT in absence of the enzyme.

\section{Construction of Sense and Antisense Rv2159c}

The sense and antisense oriented Rv2159c was cloned in pMV261 vector. The full length Rv2159c gene from M. tuberculosis was amplified using the respective oligonucleotide primers (Table S2). The amplified gene was inserted into pMV261 vector at $5^{\prime}$ BamH1 and $3^{\prime} E c o R 1$ sites to get Rv2159c in sense orientation (S-Rv2159c).

The antisense oriented Rv2159c clone was constructed in two steps. Firstly, the PCR amplified Rv2159c gene was cloned in pCR 2.1 TOPO vector with $5^{\prime} B a m H I$ and $3^{\prime} E c o R I$ sites. Further, the Rv2159c gene insert was excised from pCR 2.1 TOPO vector with $5^{\prime}$ HindIII and $3^{\prime}$ EcoRI sites. Finally, the excised Rv2159c gene insert from pCR 2.1 TOPO vector was sub-cloned into pMV261 vector at $5^{\prime}$ EcoRI and $3^{\prime}$ HindIII sites to get Rv2159c in antisense orientation (As-Rv2159c). The constructed clones were checked for orientation with SalI restriction enzyme. Product size of 
$\sim 780$ bp confirms the clone in sense orientation and the product size of $\sim 260$ bp confirms the clone in antisense orientation. The S-Rv2159c and As-Rv2159c constructs were subjected to DNA sequencing to confirm their reading frames. The sequence confirmed clones as well as empty pMV261 vector (Rv) were then electroporated into electro competent M. tuberculosis $\mathrm{H} 37 \mathrm{Rv}$ cells and plated on 7H10 agar media supplemented with OADC containing $20 \mu \mathrm{g} / \mathrm{ml}$ kanamycin.

\section{RNA Isolation and Real Time qPCR}

Total RNA was isolated from Rv, S-Rv2159c and As-Rv2159c strains at $0,3,5,7,14$, and 21 days using an RNeasy kit (QIAGEN, Inc.).). The RNA was subsequently treated with DNaseI at $37^{\circ} \mathrm{C}$ for $45 \mathrm{~min}$. The DNase was then inactivated by incubation at $75^{\circ} \mathrm{C}$ for $10 \mathrm{~min}$. RNA was quantified by using a ND1000 Nanodrop spectrophotometer (Nanodrop Technologies). Purified RNA was stored at $-80^{\circ} \mathrm{C}$. For determination of relative mRNA concentrations by qPCR, cDNA was synthesized with $1 \mu \mathrm{g}$ of RNA using QuantiTect reverse transcription kit (Qiagen), according to the manufacturer's instructions. Quantitative RTPCR primers for the Rv2159c and 16S rRNA genes were designed (Table S2). qPCRs were carried out using Taqman PCR master mix plus low ROX (Eurogentec) according to manufacturer's instructions using the Applied Biosystems 7300 real-time PCR system. To check for DNA contamination, control reactions for each sample were carried out in the absence of reverse transcriptase. The amplification conditions for all reactions were 1 cycle of $50^{\circ} \mathrm{C}$ for $2 \mathrm{~min}, 95^{\circ} \mathrm{C}$ for $10 \mathrm{~min}$, followed by 40 cycles of $95^{\circ} \mathrm{C}$ for $15 \mathrm{~s}$ and $60^{\circ} \mathrm{C}$ for $1 \mathrm{~min}$.

Analysis of $\mathrm{qPCR}$ data was carried out by relative quantification of Rv2159c gene expression using comparative CT method. For each qPCR run, the calculated threshold cycle (CT) was normalized to the CT of the internal control 16S rRNA gene amplified from the corresponding sample. Statistical analysis was carried out using GraphPad Prism software. The data presented are averages of three independent experiments and error bars represent standard deviations.

\section{Colony Morphology}

The Rv, S-Rv2159c and As-Rv2159c strains grown to mid-log phase in 7H9 medium were washed and serially diluted with phosphate-buffered-saline (PBS) containing 0.05\% Tween 80. Samples of each 10-fold dilution were spotted onto middlebrook $7 \mathrm{H} 10$ and $7 \mathrm{H} 11$ agar plates containing $20 \mu \mathrm{g} / \mathrm{ml}$ kanamycin and incubated for 4 weeks at $37^{\circ} \mathrm{C}$. Further, the plates were observed for difference in colony morphology.

\section{In vitro Growth Determinations}

To determine the in vitro growth characteristics of Rv, S-Rv2159c and As-Rv2159c strains, log-phase cultures grown in 7H9OADC-T medium with $20 \mu \mathrm{g} / \mathrm{ml}$ kanamycin were washed and diluted in fresh 7H9-OADC-T medium with appropriate antibiotics. The strains were incubated at $37^{\circ} \mathrm{C}$ with $150 \mathrm{rpm}$ shaking. Aliquots of $100 \mu \mathrm{l}$ were taken at $0,3,5,7,14$, and 21 days for measuring $\mathrm{OD}$ at $600 \mathrm{~nm}$ using spectraMax 250 microplate reader (Molecular Devices). The viability of Rv, S-Rv2159c and As-Rv2159c strains were checked at each time point by plating the serial diluted cultures in 7H10-OADC agar plates and measuring colony forming units (CFUs).

\section{Estimation of Viability under Peroxide Stress}

The Rv, S-Rv2159c and As- Rv2159c strains were grown to mid-log phase in 7H9-OADC-T medium to an $\mathrm{OD}_{600}$ of 0.1 and exposed to peroxides such as CHP (Sigma) and hydrogen peroxide (Sigma) at a concentration of $0,50,100 \mu \mathrm{M}$ and 0,10 , $20 \mathrm{mM}$ respectively. Viability of the cultures were measured at 0 , 4 , and $24 \mathrm{~h}$ by measuring CFU.

\section{D Gel Electrophoresis}

The Rv, S-Rv2159c and As-Rv2159c cell extracts were prepared and precipitated by SDS-trichloro acetic acid (TCA)-acetone method as reported earlier (Bisht et al., 2007; Sharma and Bisht, 2016). The pellets were air dried and suspended in appropriate volume of 2D-rehydration buffer (Bio-Rad, USA). The protein concentration was estimated using Bradford assay as reported earlier (Singhal et al., 2012).

Isoelectric focusing (IEF) was carried out using "in-gel rehydration" method. $7 \mathrm{~cm}$ immobilized $\mathrm{pH}$ gradient (IPG) strips of $\mathrm{pH}$ 4-7 (Bio-Rad, USA) were rehydrated overnight with $140 \mu \mathrm{g}$ protein at $20^{\circ} \mathrm{C}$. The strips were then focused on an IEF unit PROTEAN IEF Cell (Bio-Rad, USA) at $18^{\circ} \mathrm{C}$ using the following five-step program: (a) $0-250 \mathrm{~V}$ for $1.5 \mathrm{~h}$ in linear mode; (b) $250 \mathrm{~V}$ constant for $1.5 \mathrm{~h}$ in rapid mode; (c) 250-3000 V for $4 \mathrm{~h}$ in linear mode; (d) $3000 \mathrm{~V}$ constant until 15,000 Vh was reached and (e) $500 \mathrm{~V}$ constant at slow mode until the IPG strips were taken out from IEF cell. After IEF, strips were equilibrated at RT in equilibration buffer I and II (Bio-Rad, USA) for $5 \mathrm{~min}$ each and subjected to SDS-PAGE.

Gel images were acquired and analyzed by Chemidoc using Quantity One software (Bio-Rad, USA). Differentially expressed proteins were shortlisted by Student $t$-test using PDQuest software (Bio-Rad, USA). Protein spots that showed increased intensities with more than 1.5 -fold were selected for identification.

\section{Mass Spectrometry Analysis}

Differentially expressed protein spots were excised from the SDS-PAGE gels. In-gel digestion was performed for the protein spots as described (Shevchenko et al., 2006). The extracted peptides were purified using C-18 ZipTip pipette tips (Millipore, USA) and then spotted with 1:1 $\alpha$-cyano-4-hydroxycinnamic acid matrix onto an Opti-TOF 96-well MALDI plates. Peptides were analyzed on a Matrix-assisted laser desorption ionization time-of-flight (MALDI-TOF MS/MS), Daltonics Ultraflex III mass spectrometer (Bruker). The resulting MS/MS spectra were analyzed using Mascot server (http://www.matrixscience.com).

\section{Statistical Analysis}

For in vitro growth kinetics and CFU studies, two-tailed ANOVA with multiple comparisons using Bonferroni post-test was used. For Alkylhydroperoxidase assay, one-tailed ANOVA with multiple comparisons using Bonferroni post-test was used. 


\section{RESULTS}

\section{Cloning, Expression and Purification of Rv2159c}

The 1035 bp coding region of Rv2159c from M. tuberculosis was inserted at BamH1 and EcoR1 sites of pGEX 4T-1 vector. Restriction digestion and DNA sequencing confirmed plasmid was transformed into E. coli BL21 (DE3) cells for expression of Rv2159c as GST fusion protein. The construct expressed a high proportion of Rv2159c protein after $4-5 \mathrm{~h}$ of induction. The recombinant Rv2159c protein was purified to near homogeneity using glutathione sepharose affinity chromatography. Molecular mass of the purified recombinant protein was showed at 60 $\mathrm{kDa}$, which corresponds the expected molecular mass of Rv2159c protein (Figures 1A,B). For some unknown reason, the free

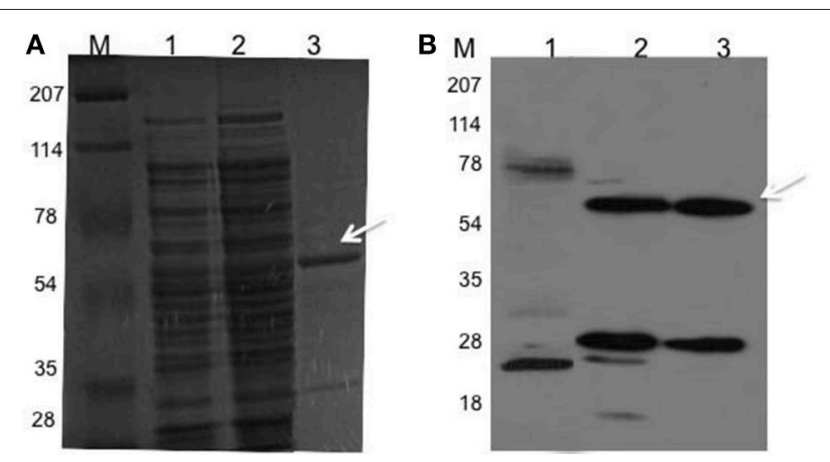

FIGURE 1 | Rv2159c cloning, expression and purification. (A,B) SDS-PAGE (12\% gel) separation of proteins and western immunoloblot with anti-GST antibody of E. coli BL21 cells expressed Rv2159c protein. Lane 1 shows the resolution of cytosolic proteins of BL21 cells (negative control); lane 2. BL21 cells expressed pDVA 2159-GST plasmid; lane 3 shows the purified recombinant GST-Rv2159c protein using glutathione sepharose affinity chromatography and lane $\mathrm{M}$, protein molecular weight ladder.
GST tag was also co-purified with Rv2159c protein as $28 \mathrm{kDa}$ protein band (Figure 1B). One possible reason could be the GST fusion tag might have degraded upon denaturation and reduction during protein gel electrophoresis.

\section{Interaction between Pknl and Rv2159c Mutants}

In our previous study, we have shown the protein kinase PknI interacts with Ala-Gly-Trp motif residues of Rv2159c (Venkatesan et al., 2015). We expanded our previous observations and confirmed the results with pull down assay using recombinant His-PknI and GST-Rv2159c proteins. Ni-NTA affinity chromatography with recombinant His-PknI protein was able to pull down GST-Rv2159c protein (Figure 2A, lane 3). In a reverse reaction, glutathione sepharose affinity chromatography with recombinant GST-Rv2159c protein was also observed to pull down His-PknI protein (Figure 2B, lane 3). In a control assay, the recombinant proteins did not pull down the tag free BSA (Figure 2, lane 4). Surprisingly, no protein phosphorylation was observed between PknI and Rv2159c (Data not shown).

To identify the residues of Rv2159c contributing to the protein interaction, the possible binding residues (Ala49, Gly50, Trp51) were mutated to proline and alanine amino acids respectively. Further, the GST-Rv2159c variants (A49P, G50A, W51A, 49AGW51) were subjected to FWB and probed with recombinant His-PknI protein. Mutation of A49P and G50A amino acids of Rv2159c protein totally abolished the interaction with $\mathrm{PknI}$ protein. However, W51 A amino acid mutation did not affect its interaction with PknI (Figure 2C). These interacting residue mutants were inactive for phosphorylation by $\mathrm{PknI}$ as WT Rv2159c (Data not shown). Together, these results confirm that only Ala49 and Gly50 amino acids of Rv2159c protein contribute to its interaction with $\mathrm{PknI}$ and no phosphorylation was involved in the interaction.

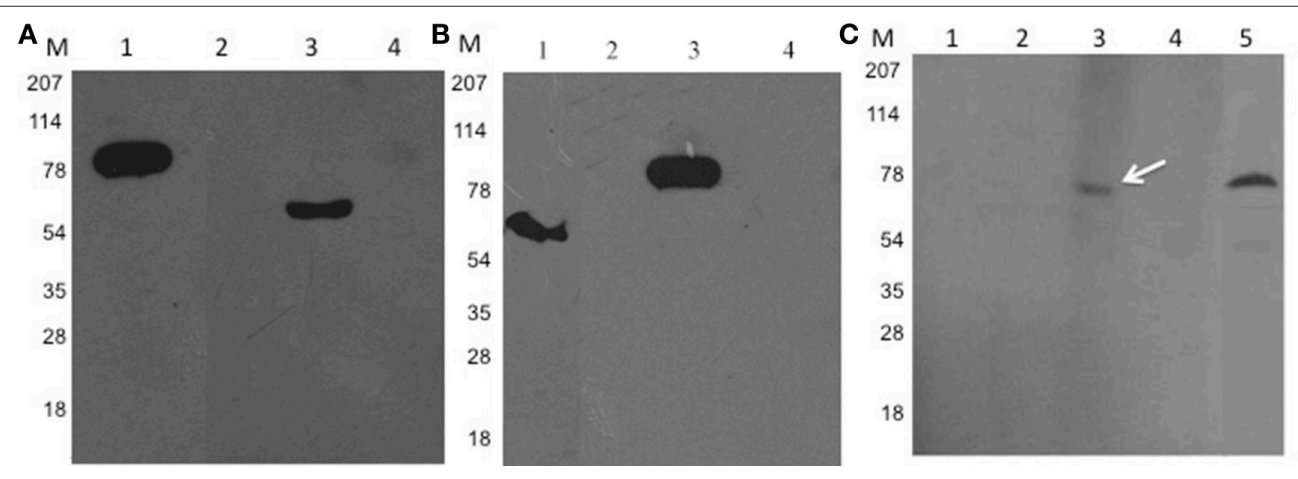

FIGURE 2 | Pknl interacts with Rv2159c. (A,B) Pull down assay confirms the interaction between Pknl and Rv2159c. Cytoplasmic crude lysates containing recombinant His-Pknl and GST-Rv2159c proteins were incubated with Ni-NTA resin (A, lane 1) or glutathione sepharose resin respectively (B, lane 1). Unbound proteins (lane 2) were washed off and incubated with their respective substrates. The protein complexes were eluted (lane 3) and immunoblotted with anti-GST (A) and anti-His antibodies (B) respectively. As a control, the bait proteins were incubated with bovine serum albumin (BSA) protein (lane 4). Lane 1 from (A) and (B) shows the bait protein load controls of Pknl and Rv2159c proteins that are probed against anti-His (A) and anti-GST (B) antibodies respectively. Several lanes were merged for photogenic purpose. (C) FWB identifies the crucial amino acids in Pknl-Rv2159c interaction. The purified GST-Rv2159c point mutants A49P (lane 1), G50A (lane 2), W51A (lane 3) and 49AGW51 (lane 4) along with purified Rv2159c protein (lane 5) were incubated with His-Pknl protein and subsequently probed with anti-His antibody. Lane M, Molecular mass standard. 


\section{Catalytic Activity of Rv2159c}

To identify the importance of two cysteine residues in catalytic site of Rv2159c protein (C-X-X-C), the cysteine amino acids were mutated to serine using site directed mutagenesis. The constructed point mutants Rv2159c_C81S, Rv2159c_C84S,

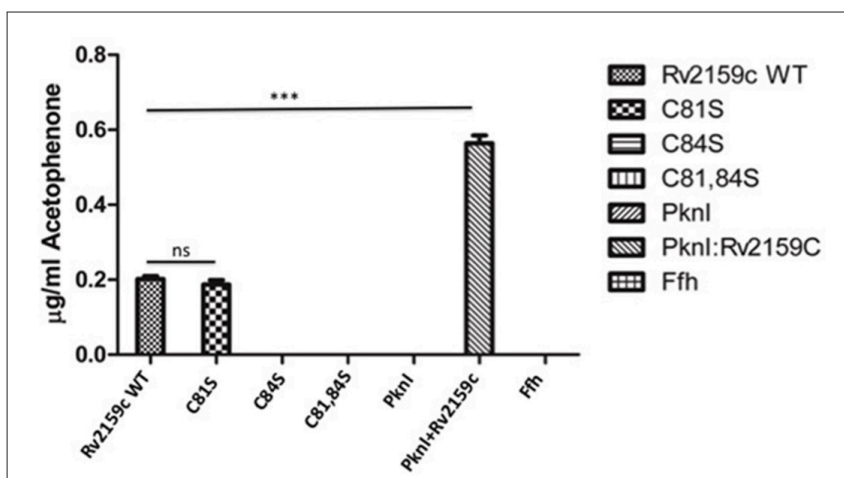

FIGURE 3 | Catalytic activity of Rv2159c and its mutants. Alkyl hydroperoxidase activity of Rv2159c variants (WT, C81S, C84S and C81,84S) were detected by measuring acetophenone using HPLC. The peroxidase activity of Rv2159c was also checked in the presence and absence of its substrate, Pknl. No catalytic activity was observed with non-specific protein (Ffh), Pknl alone and buffer control. One way ANOVA was performed. *** Indicates $P<0.001$.
Rv2159c_C81/84S were verified with DNA sequencing. The confirmed plasmids were transformed into E. coli BL21 (DE3) cells and the mutant proteins were purified to homogeneity.

The catalytic activity of Rv2159c WT and its catalytic site mutants (Rv2159c_C81S, Rv2159c_C84S, and Rv2159c_C81/84S) was detected by incubating the purified proteins with the substrate, $\mathrm{CHP}$ and the decomposed product acetophenone was measured using HPLC. Measurement of Rv2159c dependent alkylhydroperoxidase activity toward CHP revealed that the activity of Rv2159c_C81S mutant was similar to that of WT, whereas no activity was detected with Rv2159c_C84S mutant. Surprisingly, the interaction of Rv2159c WT with PknI resulted in 3-fold increase of Rv2159c's peroxidase activity (Figure 3). These results demonstrate that Rv2159c_C84S residue is responsible for Rv2159c's catalytic activity.

We next examined the possibility of two cysteine amino acids to form disulfide bridges during the catalytic activity of Rv2159c. The WT and catalytic site mutants were treated with redox agent DTT in the presence of tert-butyl hydroperoxide and the oxidation of cysteines were measured. No cysteine oxidation was detected with the Rv2159c variants suggesting the protein does not form any intramolecular disulfide bridges (Figure S1).

\section{Antisense Inhibition of Rv2159c}

In order to understand the physiological importance of Rv2159c, the differentially expressing Rv2159c strains were generated in

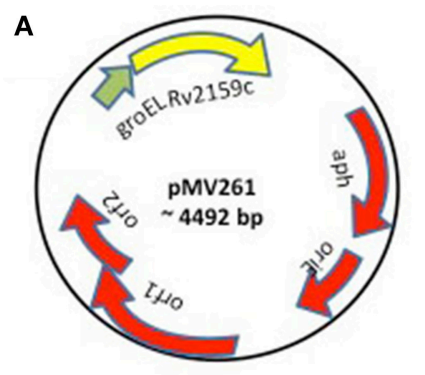

C

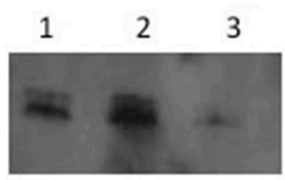

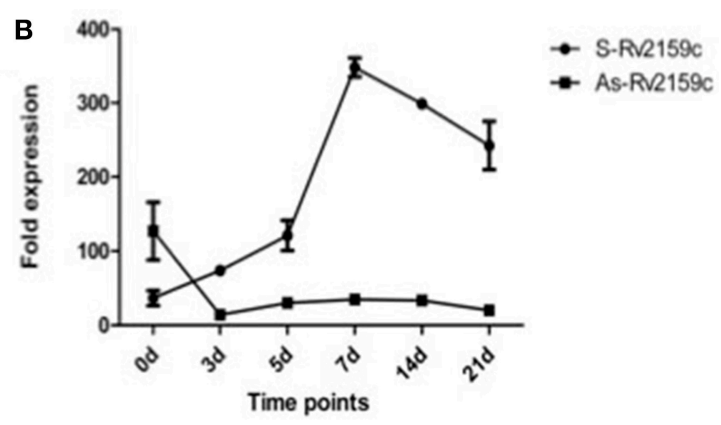

D

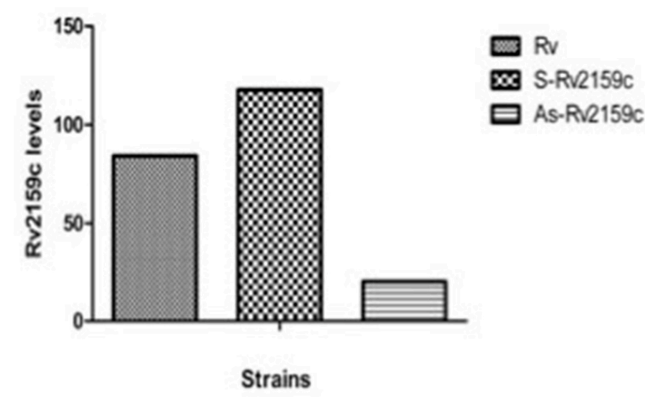

FIGURE 4 | Differential expression of Rv2159c. (A) pMV261 plasmid harboring Rv2159c in sense (S-Rv2159c) and antisense (As-Rv2159c) orientation. (B) Quantification of Rv2159c expression: Validation of Rv2159c differentially expressing constructs using quantitative real time PCR. Cell lysate of $M$. tuberculosis over-expressing (S-Rv2159c) and under-expressing (As-Rv2159c) Rv2159c gene was quantified at 0, 3, 5, 7, 14, and 21 days against the house keeping gene 16S rRNA. (C) FWB analysis for Rv2159c differentially expressing strains. Equal amount (50 $\mu \mathrm{g}$ ) of cytoplsmic lysates from $21 \mathrm{~d}$ cultures of Rv (lane 1), S-Rv2159c (lane 2) and As-Rv2159c (lane 3) strains were probed with bait protein, Pknl and anti-His antibody. (D) Quantification of Rv2159c protein band from Rv, S-Rv2159c and As-Rv2159c strains using densitometer scanning. 
M. tuberculosis strain. For this, the sense and antisense DNA strands were cloned in pMV261 vector under the $h s p$ promoter (Figure 4A). Quantification of Rv2159c transcript in S-Rv2159c and As-Rv2159c strains at different time points $(0,3,5,7,14$, and $21 \mathrm{~d})$ showed that the S-Rv2159c was induced to 347-fold on 7 $\mathrm{d}$ and later depleted to 242 -fold on $21 \mathrm{~d}$. While the As-Rv2159c strain depleted to 14 -folds on $3 \mathrm{~d}$ and maintained to 20 -fold on $21 \mathrm{~d}$ (Figure 4B). The differentially expressing strains were also quantified at protein level using FWB. When equal concentration of protein preparations from Rv, S-Rv2159c and As-Rv2159c strains were probed with PknI protein, a 33.04\% increase in S-Rv2159c and $122.17 \%$ decrease in As-Rv2159c strains were observed as compared to $\mathrm{Rv}$ (Figures 4C,D). Together, these results validated the differentially expressing Rv2159c strains.

\section{In vitro Growth of the Rv2159c Strains}

To determine whether the differential expression of Rv2159c has brought any changes in the in vitro growth, we compared the growth profiles of Rv, S-Rv2159c and As-Rv2159c strains by monitoring $\mathrm{OD}_{600}$ and quantification of CFUs at $0,3,5,7,14$, and $21 \mathrm{~d}$. No altered growth rates were observed between the strains during $\mathrm{OD}_{600}$ and survival CFU (Figures 5A,B). Analysis of the colony morphology for differentially expressing Rv2159c strains resulted in no differential colony pattern in both middlebrook 7H10 and 7H11 medium (Data not shown).

\section{Role of Rv2159c in Protection against Peroxides}

To understand the role of Rv2159c in protecting M. tuberculosis against oxidative stress, the Rv, S-Rv2159c and As-Rv2159c strains were exposed to CHP and hydrogen peroxide and CFU were determined at $0 \mathrm{~h}, 4 \mathrm{~h}$ and $24 \mathrm{~h}$ as a measure of cell viability. Exposure of S-Rv2159c to 50 and $100 \mu \mathrm{M}$ of $\mathrm{CHP}$ showed increased growth rate at $24 \mathrm{~h}$. However, exposure of AsRv2159c to CHP showed significant decrease in growth at $4 \mathrm{~h}$ and complete sterilization of the culture at $24 \mathrm{~h}$ in response to $100 \mu \mathrm{M}$ CHP (Figure 6A). Exposure of S-Rv2159c to $10 \mathrm{mM}$ hydrogen peroxide showed no difference in growth rate as compared to Rv. Whereas, exposure of As-Rv2159c to hydrogen peroxide showed decreased growth rate and complete sterilization to 20 $\mathrm{mM}$ hydrogen peroxide (Figure 6B). These results suggest that the Rv2159c gene product plays important role in oxidative stress survival of M. tuberculosis.

\section{Rv2159c Substrate Identification}

In order to identify the putative target genes of Rv2159c, the cytoplasmic lysates of Rv, S-Rv2159c and As-Rv2159c strains were separated by 2-D gel electrophoresis. Statistical analysis of the gels detected 21 spots with significant changes between Rv versus S-Rv2159c and Rv versus As-Rv2159c (Figure 7). A total of 12 protein spots could be identified using MALDI TOF TOF MS/MS analysis and they were categorized into five functional categories based on the information from Tuberculist and UniProt databases (Table 1). Most of the identified proteins were involved in intermediary metabolism and stress regulations.
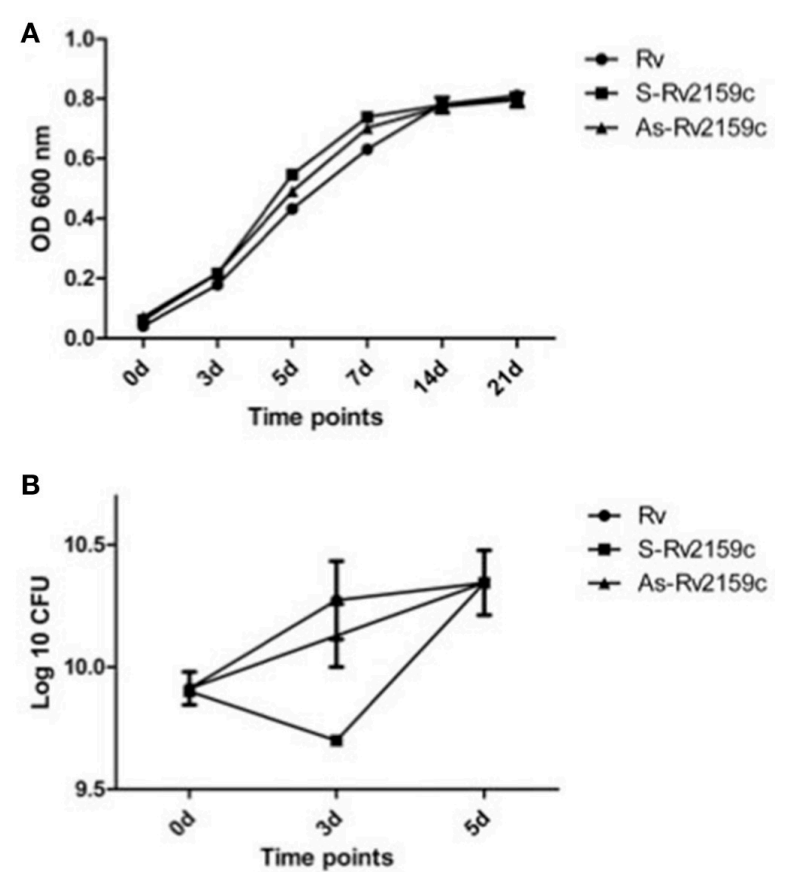

FIGURE 5 | In vitro growth kinetics of Rv2159c. (A) The S-Rv2159c and As-Rv2159c constructs in M. tuberculosis were grown in $7 \mathrm{H} 9$ supplemented medium and the growth kinetics were monitored at 0, 3, 5, 7, 14, and $21 \mathrm{~d}$. Graph represents the $\mathrm{OD}_{600}$ at different time points and represent by their mean \pm SEM from three different experiments. Comparison of Rv vs. S-Rv2159c showed a significance of $P<0.001$ at 5 and $7 \mathrm{~d}$, comparison of Rv vs. As-Rv2159c showed a significance of $P<0.05$ at day 5 and $P<0.01$ at day 7 . The statistical significance calculated by two way ANOVA using graph pad prism. (B) Survival kinetics of Rv2159c differentially expressing strains in M.tuberculosis. The S-Rv2159c and As-Rv2159c constructs in M. tuberculosis were plated in complete $7 \mathrm{H} 10$ agar plate and CFUs were measured at 0,3 , and 5 day and represent by their mean \pm SEM from three different experiments. Comparison of Rv vs. S-Rv2159c showed a significance of $P<0.05$ at day 3 .

The other functional groups such as cell wall processes and lipid metabolism related proteins are also differentially expressed.

In comparison to Rv, over-expression of Rv2159c (S-Rv2159c) leads to high abundance of two metabolic pathway proteins such as, Rv1240 (Malate dehydrogenase Mdh), Rv1827 (Glycogen accumulation regulator GarA) and low abundance of fatty acid synthesis (FAS) intermediate, Rv0636 (3-hydroxyacyl-ACP dehydratase subunit $\mathrm{HadB}$ ). Interestingly, down regulation of Rv2159c (As-Rv2159c) leads to the total absence of Rv1843c (GuaB1), an Oxidoreductase. The other proteins that are down regulated are Rv2460c (ATP-dependent CLP protease protelytic subunit 2 ClpP2), Rv3506 (Fatty acid CoA synthetase FaD17) and Rv2902c (Ribonuclease HII protein RnhB). The three stress regulated proteins, Rv2031c (Heat shock protein HspX), Rv2623 (Universal stress protein family protein TB31.7), Rv1636 (Iron-regulated universal stress protein TB15.3) and a cell wall associated protein, Rv0020c (Conserved protein with Fork Head Associated (FHA) domain FhaA) were noticed to be abundant in antisense Rv2159c strain. In summary, these analyses suggest 


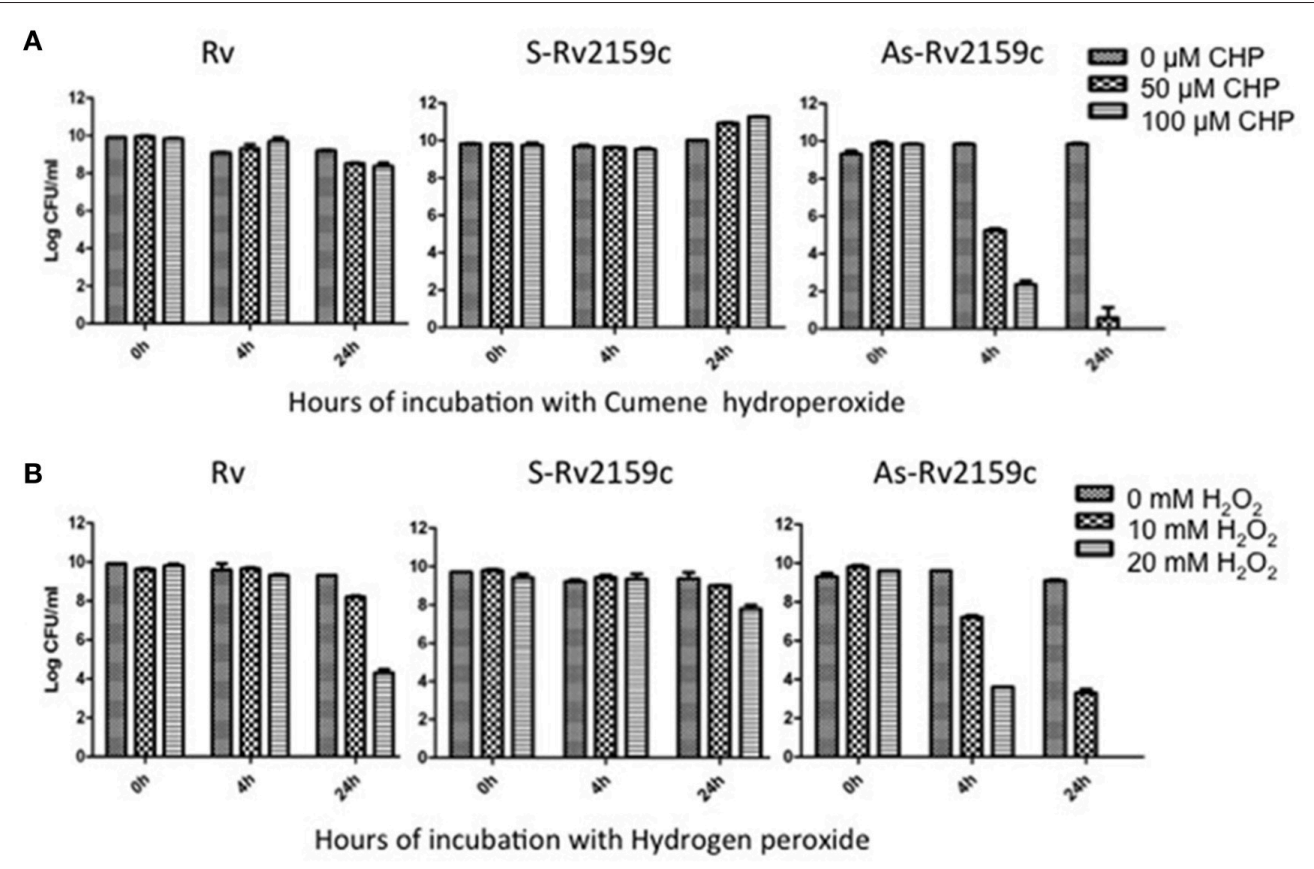

FIGURE 6 | Effect of peroxides on S-Rv2159c and As-Rv2159c. (A) The Rv, S-Rv2159c and As-Rv2159c constructs in M. tuberculosis were diluted to an OD 600 of 0.1 in complete $7 \mathrm{H} 9$ medium and CFU was measured at 0, 4, and $24 \mathrm{~h}$ post exposure with (A) 0,50 and $100 \mu \mathrm{M}$ of $\mathrm{CHP}$ and (B) 0 , 10 and 20 mM hydrogen peroxide.

that Rv2159c plays an important role in regulating intermediate metabolic pathways.

\section{DISCUSSION}

In this study, we report for the first time purification, interaction with PknI and catalytic activity of the heterologously expressed Rv2159c protein. The critical residues involved in interaction between $\mathrm{Rv} 2159 \mathrm{c}$ and $\mathrm{PknI}$ was identified and confirmed. We were able to understand the role of Rv2159c of $M$. tuberculosis using antisense expression studies and we have achieved its phenotypic characterization and substrate identification.

Rv2159c was over-expressed heterologously in soluble form as a N-terminal GST fusion protein. Mutation of two catalytic site cysteine amino acid residues (Cys81 and Cys84) identified the importance of Cys84 in alkylhydroperoxidase activity. Interestingly, the peroxidase activity of Rv2159c protein was increased to 3-fold upon its interaction with $\mathrm{PknI}$ (Figure 3). The PknI-Rv2159c interaction is mediated through phosphorylation independent physical interaction between two proteins. Mutation of active site residues of Rv2159c identified that Ala49 and Gly50 amino acids were responsible for the interaction (Figure 2C). In addition, like WT Rv2159c, no phosphorylation was observed with active site mutants of Rv2159c. These mutations could have changed the structural fold of the Rv2159c protein, so that the A49P and G50A Rv2159c mutants could not interact with $\mathrm{PknI}$ protein. However, no difference in interaction pattern was observed with catalytic site mutants (Data not shown). This denotes that the PknI interacts through the active site (Ala-Gly) of Rv2159c protein and increases its catalytic activity. To our surprise, though the Rv2159c protein is a peroxidase, it did not form disulfide bridges between the two catalytic site cysteines. Whereas, the two other alkylhydroperoxidase proteins of M. tuberculosis, AhpC and AhpD were shown to form disulfide bridges (Hillas et al., 2000).

Though the gene, Rv2159c is non-essential in M. tuberculosis, we have employed antisense strategy to elucidate its role in M. tuberculosis. However, construction of gene knockout for Rv2159c is under investigation. The use of pMV261 vector in antisense gene knockdown of $M$. tuberculosis genes has been elucidated previously (Wu et al., 2004; Sun et al., 2010; Kunisch et al., 2012). Cloning the coding sequence of sense and antisense oriented Rv2159c under hsp60 promoter of E. coli-mycobacteria shuttle vector controlled the expression of Rv2159c. qRT-PCR and FWB assessed the expression of S-Rv2159c and As-Rv2159c strains. qRT-PCR quantification of S-Rv2159c strain induced Rv2159c from day 3 and reached its maximum expression on day 7 with 347-fold expression and the As-Rv2159c down regulated from day 3 with 14 -fold expression. The differentially expressing strains from $21 \mathrm{~d}$ culture were also quantified at protein level by probing with its interacting partner, PknI. Densitometer measurements validated the S-Rv2159c and AsRv2159c constructs with $33.04 \%$ increase and $122.17 \%$ decrease in expression respectively (Figure 4). However, no difference in Rv2159c expression was noticed when the strains were exposed 


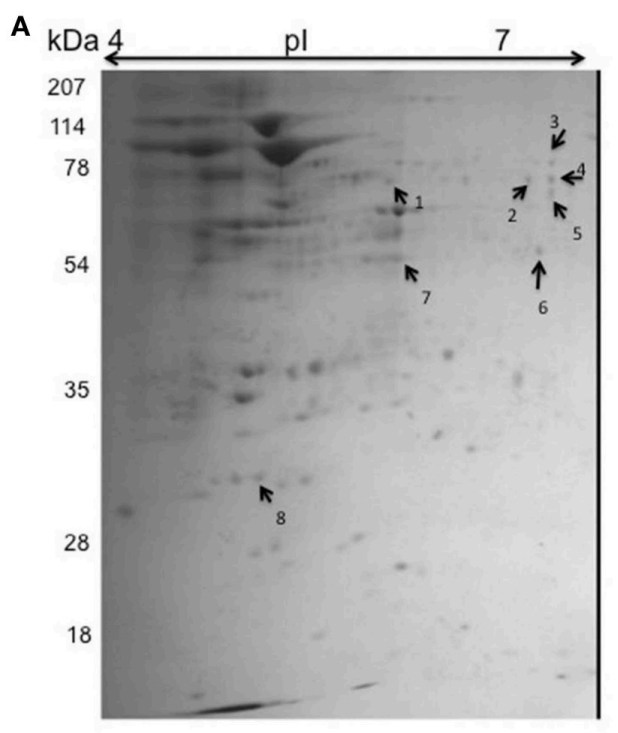

\section{B}

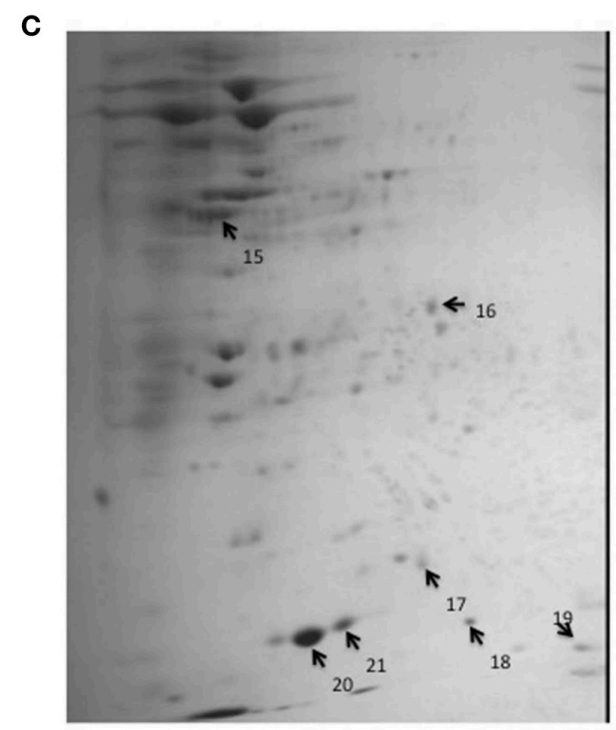

FIGURE 7 | 2D gel electrophoresis for S-Rv2159c and As-Rv2159c strains. The cytoplasmic cell extracts of S-Rv2159c, As-Rv2159c and Rv constructs in M. tuberculosis were subjected to 2D gel electrophoresis. The CBB R250 stained gels (A) Rv, (B) S-Rv2159c, and (C) As-Rv2159c were shown. The arrow marks represents the difference in spots using PDQuest software were analyzed by mass spectrometry.

with and without heat induction at $42^{\circ} \mathrm{C}$ to induce the $h s p$ promoter (Data not shown).

There were no morphological changes associated with colony morphology of differentially expressing Rv2159c strains. The differential expressing Rv2159c strains did not differ in their growth kinetics. Interestingly, knockdown of Rv2159c showed decrease growth rate, which denotes its sensitivity against CHP and hydrogen peroxide stresses. In the other hand, over-expression of Rv2159c resulted in increased growth rate of the bacilli (Figure 6). Thus, the differential growth rate of $\mathrm{Rv} 2159 \mathrm{c}$ strains suggested that the gene is responsible for protection against oxidative stresses of the bacteria.
Out of 21 differentially expressed proteins identified by 2D gel electrophoresis, only 12 proteins could be identified using MALDI TOF-TOF MS/MS analysis. The remaining 9 proteins spots could not be identified because the amount of proteins was too small and no satisfactory spectrum was available. Over-expression of Rv2159c induces metabolic pathway related proteins, suggesting a possible role of Rv2159c in M. tuberculosis metabolism. Both the substrates, Mdh (Rv1240) and GarA (Rv1827) are TCA cycle regulators, where the malate dehydrogenase oxidizes the conversion of malate to oxaloacetate and glycogen accumulation regulatory protein GarA (Rv1827), acts as a key metabolic intermediate for the enzymes that use $\alpha$-ketoglutarate (Ventura et al., 2013; Wang et al., 2015). 
TABLE 1 | Identification of the differentially regulated 2D protein spots of Rv, S-Rv2159c, and As-Rv2159c.

\begin{tabular}{|c|c|c|c|c|c|c|c|}
\hline Spot no. & Gene name & Accession no. & Mascot score & $\begin{array}{l}\text { No. of matched } \\
\text { peptides }\end{array}$ & Gene index & $\begin{array}{l}\text { Theoretical } \\
\mathrm{pl} / \mathrm{kDa}\end{array}$ & Expression \\
\hline \multicolumn{8}{|c|}{ GROUP 1: INTERMEDIARY METABOLISM, RESPIRATION } \\
\hline 4 & $\begin{array}{l}\text { Uncharacterised oxidoreductase, } \\
\text { GuaB1 }\end{array}$ & Rv1843c & 69 & 1 & gi 492067680 & $6.29 / 49.93$ & $\begin{array}{l}\text { Absent in } \\
\text { AsRv2159c }\end{array}$ \\
\hline 8 & $\begin{array}{l}\text { ATP-dependent CLP protease } \\
\text { protelytic subunit 2, ClpP2 }\end{array}$ & Rv2460c & 74 & 4 & gi 15609597 & $4.75 / 23.5$ & $\begin{array}{l}\text { Absent in } \\
\text { As-Rv2159c }\end{array}$ \\
\hline $9,10,11$ & Malate dehydrogenase, Mdh & Rv1240 & 496 & 4 & gi 489501402 & $4.39 / 34.28$ & $\begin{array}{l}\text { More in } \\
\text { S-Rv2159c }\end{array}$ \\
\hline 12 & $\begin{array}{l}\text { Glycogen accumulation } \\
\text { regulator, GarA }\end{array}$ & Rv1827 & 457 & 3 & gi 240104237 & $4.06 / 17.21$ & $\begin{array}{l}\text { More in } \\
\text { S-Rv2159c }\end{array}$ \\
\hline \multicolumn{8}{|c|}{ GROUP 2: VIRULENCE, DETOXIFICATION AND ADAPTATION } \\
\hline 16 & $\begin{array}{l}\text { Universal stress protein family } \\
\text { protein, TB31.7 }\end{array}$ & Rv2623 & 800 & 6 & gi 685981944 & $5.55 / 31.65$ & $\begin{array}{l}\text { Present in } \\
\text { AsRv2159c }\end{array}$ \\
\hline 18 & $\begin{array}{l}\text { Iron-regulated universal stress } \\
\text { protein family protein, TB15.3 }\end{array}$ & Rv1636 & 243 & 3 & gi 669108828 & $5.62 / 15.31$ & $\begin{array}{l}\text { More in } \\
\text { AsRv2159c }\end{array}$ \\
\hline 20,21 & Heat shock protein, HspX & Rv2031c & 327 & 3 & gi 801196443 & $4.75 / 16.22$ & $\begin{array}{l}\text { Present only } \\
\text { in AsRv2159c }\end{array}$ \\
\hline \multicolumn{8}{|c|}{ GROUP 3: LIPID METABOLISM } \\
\hline 7 & $\begin{array}{l}\text { Fatty acid CoA synthetase, } \\
\text { FaD17 }\end{array}$ & Rv3506 & 79 & 2 & gi 764899599 & $4.93 / 53.73$ & $\begin{array}{l}\text { Less in } \\
\text { As-Rv2159c }\end{array}$ \\
\hline 14 & $\begin{array}{l}\text { 3-hydroxyacyl-ACP dehydratase } \\
\text { subunit, HadB }\end{array}$ & Rv0636 & 83 & 1 & gi 686051919 & $6.52 / 14.93$ & $\begin{array}{l}\text { More in } \\
\text { S-Rv2159c }\end{array}$ \\
\hline \multicolumn{8}{|c|}{ GROUP 4: CELL WALL AND CELL PROCESSES } \\
\hline 15 & $\begin{array}{l}\text { Conserved protein with FHA } \\
\text { domain, FhaA }\end{array}$ & Rv0020c & 399 & 3 & gi 15607162 & $4.65 / 56.88$ & $\begin{array}{l}\text { More in } \\
\text { AsRv2159c }\end{array}$ \\
\hline \multicolumn{8}{|c|}{ GROUP 5: INFORMATION PATHWAY } \\
\hline 6 & Ribonuclease HIl protein, RnhB & Rv2902c & 64 & 3 & gi 686045826 & $10.47 / 27.64$ & $\begin{array}{l}\text { Absent in } \\
\text { AsRv2159c }\end{array}$ \\
\hline
\end{tabular}

Interestingly, over-expression of Rv2159c accumulated type II FAS intermediate HadB (Rv0636) and under-expression of Rv2159c depleted type I FAS intermediate, FaD17 (Rv3506).

Loss of Rv2159c induces three stress proteins, in which the $16 \mathrm{kDa}$ heat shock protein HspX (Rv2031c) and universal stress protein family protein TB 31.7 aids in preventing misfolding of M. tuberculosis proteins under stress conditions. Both the HspX (Rv2031c) and TB 31.7 (Rv2623) also showed increase in their expression during dormancy conditions (Drumm et al., 2009; Dubaniewicz et al., 2013). However, the iron-regulated universal stress protein, TB15.3 (Rv1636) was shown to provide only a generalized stress response. Another protein that was down regulated in As-Rv2159c strain was also shown to be important in bacterial stresses. The proteolytic degradation component, ClpP2 ( $\mathrm{Rv} 2460 \mathrm{c})$ is a core subunit of proteasome complex and it was observed to be up regulated under stress conditions (Mehra and Kaushal, 2009). Down regulation of Rv2159c also induced a FHA domain containing protein Rv0020c. FhaA is a substrate of cell division regulator protein, $\mathrm{PknB}$ (Roumestand et al., 2011).

The absence of GuaB1 (Rv1843c) was unique to the proteomic profile of As-Rv2159c. The two orthologs of GuaB1 such as GuaB2 and GuaB3 together forms an operon, whereas the GuaB1 is present elsewhere in the genome. Biochemical characterisation of $\mathrm{GuaB}$ ortholog suggested the potential role of GuaB2 in Inosine monophosphate dehydrogenase activity, whereas the role of GuaB1 and GuaB3 is still unknown (Usha et al., 2011). The gene ontology of molecular function classifies GuaB1 as an uncharacterized oxidoreductase. Taken together, we hypothesize that the oxidoreductase, GuaB1 (Rv1843c) could be a probable substrate for the alkylhydroperoxidase, Rv2159c and they both could act together during oxidative stresses. But, identification of Rv2159c substrates under oxidative stress conditions would completely unravel the other probable substrates of Rv2159c.

Protein kinases control every aspect of cellular functions through signal transduction. The STPK, PknI was shown to be involved in cell division and virulence of $M$. tuberculosis (Kandasamy et al., 2014). Deletion of the pknI gene leads to increased bacillary load in severe combined immunodeficiency (SCID) mice organs than its parental strain. In addition, the $p k n I$ deletion mutant was reported to grow well in low $\mathrm{pH}$ and low oxygen conditions that mimics the macrophage environment (Gopalaswamy et al., 2009). This study addresses the role of PknI in regulating $M$. tuberculosis during oxidative stress condition. Our results indicates that $\mathrm{PknI}$ as a kinase protein senses the hypoxic environment of the bacteria and interacts with redox protein Rv2159c in cytosol and thereby maintains the cellular homeostasis.

In summary, Rv2159c adds to the peroxidase group of proteins in M. tuberculosis. Protein interaction and phosphorylation studies showed that the Rv2159c protein communicates with 
PknI only through Ala49 and Gly50 amino acids and there is no phosphorylation involved in the interaction. Also, interaction with PknI rapidly increased Rv2159c's peroxidase activity. Knockdown of Rv2159c leads to total susceptibility to peroxides. Our studies also indicated that, Rv2159c regulates various functions such as intermediate metabolism, lipid metabolism and stress regulations await further confirmation. Experiments are in progress to determine the virulence of Rv2159c in in vitro and in vivo systems.

\section{AUTHOR CONTRIBUTIONS}

SN: Conceived and supervised the study; AV and KP: Designed experiments; AV: Conducted most of the experiments, analyzed the results and wrote the manuscript. DS: Conducted the experiments involving 2D gel electrophoresis; DB: Provided technical support for performing 2DIGE.

\section{REFERENCES}

Av-Gay, Y., and Everett, M. (2000). The eukaryotic-like Ser/Thr protein kinases of Mycobacterium tuberculosis. Trends Microbiol. 8, 238-244. doi: 10.1016/S0966842X(00)01734-0

Baess, I. (1974). Isolation and purification of deoxyribonucleic acid from mycobacteria. Acta Pathol. Microbiol. Scand. B. Microbiol. Immunol. 82, 780-784. doi: 10.1111/j.1699-0463.1974.tb02375.x

Bisht, D., Singhal, N., Sharma, P., and Venkatesan, K. (2007). An improved sample preparation method for analyzing mycobacterial proteins in twodimensional gels. Biochem. Mosc. 72, 672-674. doi: 10.1134/S00062979070 60119

Bretl, D. J., Demetriadou, C., and Zahrt, T. C. (2011). Adaptation to environmental stimuli within the host: two-component signal transduction systems of Mycobacterium tuberculosis. Microbiol. Mol. Biol. Rev. 75, 566-582. doi: 10.1128/MMBR.05004-11

Cooper, A. M., Segal, B. H., Frank, A. A., Holland, S. M., and Orme, I. M. (2000). Transient loss of resistance to pulmonary tuberculosis in $\mathrm{p} 47^{\text {phox-/- }}$ mice. Infect. Immun. 68, 1231-1234. doi: 10.1128/IAI.68.3.1231-1234.2000

Deretic, V., Philipp, W., Dhandayuthapani, S., Mudd, M. H., Curcic, R., Garbe, T., et al. (1995). Mycobacterium tuberculosis is a natural mutant with an inactivated oxidative-stress regulatory gene: implications for sensitivity to isoniazid. Mol. Microbiol. 17, 889-900. doi: 10.1111/j.1365-2958.1995.mmi_170 50889.x

Drumm, J. E., Mi, K., Bilder, P., Sun, M., Lim, J., Bielefeldt-Ohmann, H., et al. (2009). Mycobacterium tuberculosis universal stress protein Rv2623 regulates bacillary growth by ATP-Binding: requirement for establishing chronic persistent infection. PLoS Pathog. 5:e1000460. doi: 10.1371/ journal.ppat.1000460

Dubaniewicz, A., Holownia, A., Kalinowski, L., Wybieralska, M., Dobrucki, I. T., and Singh, M. (2013). Is mycobacterial heat shock protein $16 \mathrm{kDa}$, a marker of the dormant stage of Mycobacterium tuberculosis, a sarcoid antigen? Hum. Immunol. 74, 45-51. doi: 10.1016/j.humimm.2012.10.007

Golby, P., Hatch, K. A., Bacon, J., Cooney, R., Riley, P., Allnutt, J., et al. (2007). Comparative transcriptomics reveals key gene expression differences between the human and bovine pathogens of the Mycobacterium tuberculosis complex. Microbiology 153(Pt 10), 3323-3336. doi: 10.1099/mic.0.2007/009894-0

Gopalaswamy, R., Narayanan, P. R., and Narayanan, S. (2004). Cloning, overexpression, and characterization of a serine/threonine protein kinase $\mathrm{pknI}$ from Mycobacterium tuberculosis H37Rv. Protein Expr. Purif. 36, 82-89. doi: 10.1016/j.pep.2004.03.011

Gopalaswamy, R., Narayanan, S., Chen, B., Jacobs, W. R., and Av-Gay, Y. (2009). The serine/threonine protein kinase PknI controls the growth of

\section{ACKNOWLEDGMENTS}

AV would like to acknowledge Indian Council for Medical Research (ICMR) for providing Senior Research Fellowship. We also like to thank Dr. Sivaraman veeramani, Dr. Hemanth kumar, and Dr. Kiran kumar for their help in HPLC experiment.

\section{SUPPLEMENTARY MATERIAL}

The Supplementary Material for this article can be found online at: http://journal.frontiersin.org/article/10.3389/fmicb. 2016.01654

Figure S1 | DTT oxidation assay for Rv2159c. Quantification of cysteine oxidation with Rv2159c WT and its catalytic site mutants (C81S, C84S, C81/84S) in the presence of DTT.

Table S1 | List of constructs used in this study.

Table S2 | Details of primers used in this study.

Mycobacterium tuberculosis upon infection. FEMS Microbiol. Lett. 295, 23-29. doi: 10.1111/j.1574-6968.2009.01570.x

Guimarães, B. G., Souchon, H., Honoré, N., Saint-Joanis, B., Brosch, R., Shepard, W., et al. (2005). Structure and mechanism of the alkyl hydroperoxidase AhpC, a key element of the Mycobacterium tuberculosis defense system against oxidative stress. J. Biol. Chem. 280, 25735-25742. doi: 10.1074/jbc.M503076200

Hillas, P. J., del Alba, F. S., Oyarzabal, J., Wilks, A., and Ortiz De Montellano, P. R. (2000). The AhpC and AhpD antioxidant defense system of Mycobacterium tuberculosis. J. Biol. Chem. 275, 18801-18809. doi: 10.1074/jbc.M001001200

Kandasamy, S., Hassan, S., Gopalaswamy, R., and Narayanan, S. (2014). Homology modelling, docking, pharmacophore and site directed mutagenesis analysis to identify the critical amino acid residue of PknI from Mycobacterium tuberculosis. J. Mol. Graph. Model. 52, 11-19. doi: 10.1016/j.jmgm.2014.05.011

Kaufmann, S. H., and Parida, S. K. (2007). Changing funding patterns in tuberculosis. Nat. Med. 13, 299-303. doi: 10.1038/nm0307-299

Kunisch, R., Kamal, E., and Lewin, A. (2012). The role of the mycobacterial DNA-binding protein 1 (MDP1) from Mycobacterium bovis BCG in host cell interaction. BMC Microbiol. 12:165. doi: 10.1186/1471-2180-12-165

Li, A. H., Waddell, S. J., Hinds, J., Malloff, C. A., Bains, M., Hancock, R. E., et al. (2010). Contrasting transcriptional responses of a virulent and an attenuated strain of Mycobacterium tuberculosis infecting macrophages. PLoS ONE 5:e11066. doi: 10.1371/journal.pone.0011066

Macmicking, J. D., North, R. J., Lacourse, R., Mudgett, J. S., Shah, S. K., and Nathan, C. F. (1997). Identification of nitric oxide synthase as a protective locus against tuberculosis. Proc. Natl. Acad. Sci. U.S.A. 94, 5243-5248. doi: 10.1073/pnas.94.10.5243

Mehra, S., and Kaushal, D. (2009). Functional genomics reveals extended roles of the Mycobacterium tuberculosis stress response factor sigmaH. J. Bacteriol. 191, 3965-3980. doi: 10.1128/JB.00064-09

Munshi, T., Gupta, A., Evangelopoulos, D., Guzman, J. D., Gibbons, S., Keep, N. H., et al. (2013). Characterisation of ATP-dependent Mur ligases involved in the biogenesis of cell wall peptidoglycan in Mycobacterium tuberculosis. PLoS ONE 8:e60143. doi: 10.1371/journal.pone.0060143

Roumestand, C., Leiba, J., Galophe, N., Margeat, E., Padilla, A., Bessin, Y., et al. (2011). Structural insight into the Mycobacterium tuberculosis Rv0020c protein and its interaction with the PknB kinase. Structure 19, 1525-1534. doi: 10.1016/j.str.2011.07.011

Sharma, D., and Bisht, D. (2016). An efficient and rapid method for enrichment of lipophilic proteins from Mycobacterium tuberculosis $\mathrm{H} 37 \mathrm{Rv}$ for two-dimensional gel electrophoresis. Electrophoresis 37, 1187-1190. doi: 10.1002/elps.201600025

Sherman, D. R., Mdluli, K., Hickey, M. J., Arain, T. M., Morris, S. L., Barry, C. E. III, et al. (1996). Compensatory ahpC gene expression in 
isoniazid-resistant Mycobacterium tuberculosis. Science 272, 1641-1643. doi: $10.1126 /$ science. 272.5268 .1641

Shevchenko, A., Tomas, H., Havlis, J., Olsen, J. V., and Mann, M. (2006). In-gel digestion for mass spectrometric characterization of proteins and proteomes. Nat. Protoc. 1, 2856-2860. doi: 10.1038/nprot.2006.468

Singhal, N., Sharma, P., Kumar, M., Joshi, B., and Bisht, D. (2012). Analysis of intracellular expressed proteins of Mycobacterium tuberculosis clinical isolates. Proteome Sci. 10:14. doi: 10.1186/1477-5956-10-14

Sun, J., Wang, X., Lau, A., Liao, T. Y., Bucci, C., and Hmama, Z. (2010). Mycobacterial nucleoside diphosphate kinase blocks phagosome maturation in murine RAW 264.7 macrophages. PLOS ONE 5:e8769. doi: 10.1371/ journal.pone.0008769

Usha, V., Gurcha, S. S., Lovering, A. L., Lloyd, A. J., Papaemmanouil, A., Reynolds, R. C., et al. (2011). Identification of novel diphenyl urea inhibitors of Mt-GuaB2 active against Mycobacterium tuberculosis. Microbiology 157(Pt 1), 290-299. doi: 10.1099/mic.0.042549-0

Venkatesan, A., Hassan, S., Palaniyandi, K., and Narayanan, S. (2015). In silico and experimental validation of protein-protein interactions between $\mathrm{PknI}$ and Rv2159c from Mycobacterium tuberculosis. J. Mol. Graph. Model. 62, 283-293. doi: 10.1016/j.jmgm.2015.10.011

Ventura, M., Rieck, B., Boldrin, F., Degiacomi, G., Bellinzoni, M., Barilone, N., et al. (2013). GarA is an essential regulator of metabolism in Mycobacterium tuberculosis. Mol. Microbiol. 90, 356-366. doi: 10.1111/mmi. 12368
Wang, X. M., Soetaert, K., Peirs, P., Kalai, M., Fontaine, V., Dehaye, J. P., et al. (2015). Biochemical analysis of the NAD+-dependent malate dehydrogenase, a substrate of several serine/threonine protein kinases of Mycobacterium tuberculosis. PLoS ONE 10:e0123327. doi: 10.1371/journal.pone.0123327

World Health Organisation (2014). Global Tuberculosis Report 2014 WHO/HTM/TB/2014. Geneva: World Health Organisation

Wu, S., Howard, S. T., Lakey, D. L., Kipnis, A., Samten, B., Safi, H., et al. (2004). The principal sigma factor sigA mediates enhanced growth of Mycobacterium tuberculosis in vivo. Mol. Microbiol. 51, 1551-1562. doi: 10.1111/j.13652958.2003.03922.x

Wu, Y., Li, Q., and Chen, X. Z. (2007). Detecting protein-protein interactions by Far western blotting. Nat. Protoc. 2, 3278-3284. doi: 10.1038/nprot.2007.459

Conflict of Interest Statement: The authors declare that the research was conducted in the absence of any commercial or financial relationships that could be construed as a potential conflict of interest.

Copyright (c) 2016 Venkatesan, Palaniyandi, Sharma, Bisht and Narayanan. This is an open-access article distributed under the terms of the Creative Commons Attribution License (CC BY). The use, distribution or reproduction in other forums is permitted, provided the original author(s) or licensor are credited and that the original publication in this journal is cited, in accordance with accepted academic practice. No use, distribution or reproduction is permitted which does not comply with these terms. 